праздник, который назывался 元宵节/yuánxiāojié/ (Праздник фонарей), обучаемый осознает, что в честь этого праздника и получили свое название 元宵/yuánxiāo/ - и шарики из риса с разнообразной начинкой, которые являются традиционным блюдом в этот день. Очевидно, что такой подход позволяет более полно охватить языковую картину мира и лучше понять культуру изучаемого языка. Вследствие этого у обучаемых расширяется потенциал ведения межкультурного диалога [6, с. 149]. Более того, такой подход позволяет повысить качество восприятия информации на китайском языке и грамотно адаптировать ее для восприятия при переводе.

Для успешного формирования социокультурной компетенции обучаемых важно учитывать их уровень знаний, возраст, жизненный опыт и т. д. Для обучаемых с высоким уровнем знаний можно расширять и углублять культурный компонент преподавания языка, вплоть до введения специальных занятий по культуре Китая. Для тех же, чей уровень довольно низок, следует максимально облегчить момент интеграции культурного компонента и не акцентировать на нем внимание слишком сильно [6, с. 149]. Такой подход позволяет в значительной мере оптимизировать процесс обучения и сделать его более плодотворным, что в свою очередь демонстрирует важность дифференцированного подхода к подаче материала в зависимости от уровня личной культуры обучаемых.

\section{УДК 378}

Науч. спец. 13.00 .08

DOI: $10.36809 / 2309-9380-2020-26-100-103$

\section{ФОРМИРОВАНИЕ КРИТИЧЕСКОЙ ОСОЗНАННОСТИ В МЕЖКУЛЬТУРНОЙ КОММУНИКАЦИИ ПРИ ПОДГОТОВКЕ УЧИТЕЛЯ ИНОСТРАННОГО ЯЗЫКА}

В статье критическая межкультурная осознанность рассматривается как компонент межкультурной коммуникативной компетенции учителя иностранного языка. Показано, что критическая осознанность в межкультурной коммуникации базируется на сложной совокупности нескольких видов знания (языкового, метаязыкового, социокультурного; декларативного, процедурного) и ценностно-смыслового отношения к культурам родного и иностранного языков. Обсуждаются пути формирования межкультурной осознанности в процессе профессиональной подготовки педагогов. Обосновывается необходимость усиления сравнительно-сопоставительного аспекта в преподавании языка и культуры в вузе, развития у будущих учителей умений сопоставительного лингвистического и лингводидактического анализа, повышения уровня дискурсивной компетенции в области межкультурного взаимодействия.

Ключевые слова: иноязычное образование, профессиональная подготовка педагога, межкультурная компетентность, сопоставительный культурологический анализ, критический дискурс-анализ.
1. Гальскова Н. Д., Гез Н. И. Теория обучения иностранным языкам: Лингводидактика и методика : учеб. пособие для студ. лингв. ун-тов и фак. ин. яз. высш. пед. учеб. заведений. М. : Изд. центр «Академия», 2004. 336 с.

2. Тарева Е. Г. Система культуросообразных подходов к обучению иностранному языку // Язык и культура. 2017. № 40. C. 302-320.

3. Сафонова В. В. Изучение языков международного общения в контексте диалога культур и цивилизаций. Воронеж : Истоки, 1996. 237 с.

4. Сафонова В.В.Культуроведческий ракурс современного языкового образования // Учен. зап. Нац. о-ва прикладной лингвистики. 2013. № 2 (2). С. 26-46.

5. Чиркова В. М. Теоретическая модель формирования социокультурной компетенции // Вестн. Костром. гос. ун-та. 2008. № 14 (4) С. 356-360.

6. 王勇. 中俄文化差异与对俄汉语教学 // 学理论. 2009. № 8. 第148-149 页。

7. 陈光磊. 语言教学与文化背景知识的相关性. 语 言教学与研. 1987. 第2期. 第146页。

(С) Дворцова А. Н., Акиншева И. П., 2020

\title{
TRAINING OF CRITICAL INTERCULTURAL AWARENESS IN FOREIGN LANGUAGE TEACHERS' EDUCATION
}

The paper regards critical intercultural awareness as the component of second language teachers' intercultural communicative competence. It is stated that intercultural awareness is based upon the complex unity of several types of knowledge (linguistic, metalinguistic, socio-cultural; declarative, procedural) and meaning-value-attitude assumptions regarding the first language and the second language cultures. The paper discusses the ways of intercultural awareness training as part of second language teachers' education. The key role of the comparative studies approach in teachers' training is highlighted. It is shown that enhanced skills of comparative linguistic analysis and comparative cultural analysis as well as enhanced intercultural discourse competence in second language teachers provide the necessary background for critical intercultural awareness.

Keywords: foreign language education, teachers' professional training, intercultural competence, comparative cultural analysis, critical discourse analysis. 
Развитие критичности, рефлексивности мышления является одним из современных требований к профрессиональной подготовке педагога. Учитель иностранного языка сегодня позиционируется как специалист, который способен критически воспринять инокультурный социальный опыт, освоить его и использовать в образовательных целях, в первую очередь для создания коммуникативной среды на уроке, максимально приближенной к аутентичной. Научное обсуждение проблемы профессиональной компетенции учителя потребовало введения в научный оборот понятия критической межкультурной осознанности, которое отражает наиболее существенные свойства процессов осмысления культуры изучаемого языка и интериоризации инокультурного опыта.

В лингводидактике каноническим считается следующее определение критической осознанности, предложенное М. Байрамом в рамках разработки авторской модели межкультурной коммуникативной компетенции: «Критическая межкультурная осознанность - это способность критически, на основе эксплицитных критериев оценивать перспективы, практики и продукты собственной культуры и культуры других стран» (перевод наш. - Е. Д., Т. У.) [1, р. 53]. По М. Байраму, критическая межкультурная осознанность является частью межкультурной компетенции наряду с выработанным отношением к культуре языка, языковыми и социокультурными знаниями, умениями интерпретации артефактов и событий другой культуры и умениями межкультурного взаимодействия [1].

Становление отношения к культуре изучаемого языка является чрезвычайно сложной задачей, реализация которой начинается именно с создания условий для появления у обучающего критической осознанности и выработки собственной этической позиции [2]. Образующееся в процессе обучения отношение к изучаемому языку и культуре нельзя рассматривать в узкой прагматической перспективе обмена коммуникативными сообщениями. Сегодня межкультурное взаимодействие представляет собой коммуникативные отношения в контексте культурного многообразия [2], и успешность этих отношений определяется умением коммуникантов критически переосмыслить инокультурные ценности, паттерны поведения, формы организации жизнедеятельности и т. п. Такое качество современной межкультурной коммуникации определяет новые требования к подготовке учителя иностранного языка как специалиста, обладающего неотъемлемыми признаками интеркультурной языковой личности: культурным интеллектом [3] и межкультурной эфрфективностью [4], образование которых невозможно без критической осознанности.

Актуальность настоящего исследования обусловлена необходимостью расширения научных представлений о качествах вторичной языковой личности и структуре компетентности педагога, специализирующегося в преподавании иностранного языка и культуры. В настоящей работе проблема формирования критической межкультурной осознанности рассматривается с позиции «критического поворота» в современной лингводидактике [5; 6 и др.]. «Критический поворот», произошедший за последнее десятилетие как в теории обучения иностранным языкам и культурам, так и в повседневной практике межкультурной коммуникации, ознаменовал собой качественное изменение субъекта ком- муникативной деятельности [6]. Понимание субъекта межкультурной коммуникации как индивида, усваивающего набор устоявшихся норм и кодов другой культуры, сменилось актуализацией динамического аспекта межкультурного взаимодействия. Субъект межкультурной коммуникации сегодня понимается как коммуникативная личность, критически осмысливающая межкультурное взаимодействие и совершающая осознанные выборы (социальные, этические, политические и др.) в динамически изменяющихся коммуникативных ситуациях межкультурного общения [6].

Развитие критического мышления и рефлексивной позиции учителя иностранного языка как субъекта межкультурной коммуникации требует прочной знаниевой основы. Сложная совокупность декларативного знания (знать что) и процедурного знания (знать как) создает основу системы критических суждений в области межкультурного взаимодействия. Критическая межкультурная осознанность должна проявляться прежде всего в знании учителем иностранного языка типов взаимовлияния культур и типов межкультурных контактов. Как известно, в теории межкультурной коммуникации выделяют четыре типа межкультурных контактов - соприкосновение, приобщение, проникновение, взаимодействие [7, с. 107-115] - в зависимости от способа учета коммуникантами социокультурных стереотипов культуры родного языка (Я1) и культуры изучаемого языка (Я2). Сегодня межкультурное знание, формируемое у учителяиностранного языка, должно основываться на понимании того, что межкультурное взаимодействие представляет собой трансфрер культурных концептов, степень присвоения которых может варьироваться в зависимости от целей коммуникации. Как подчеркивает Д. Б. Гудков, «необходимо исходить из принципа учета инофоном определенных категорий и моделей новой для него культуры и адекватного пользования ими, но не из обязательности их присвоения, не нужно стремиться к тому, чтобы они заняли место тех категорий и моделей, которые характерны для его родной культуры» [8, с. 88]. Например, в Китае концептуализация изучаемой культуры на фоне родной рассматривается сегодня как ведущая тема в иноязычном образовании. В частности, стремление преодолеть доминирование англоговорящих культур в преподавании английского языка определяется как насущная необходимость в современных реалиях, когда английский язык глобально используется как язык-посредник в общении людей различной культурной принадлежности [9].

Целостность ценностно-смыслового компонента в структуре критической межкультурной осознанности учителя иностранного языка должна определяться сформированностью 1) приоритетного осознания собственной культурной идентичности (культурной идентичности Я1) и высочайшей ценности родной культуры; 2) общей психологической готовности к межкультурному взаимодействию на основе толерантного восприятия культурного разнообразия человечества («межкультурной эмпатии» в понимании [10]); 3) уважительного отношения к родной и изучаемой культурам, выработанного на основе глубокого знания этих культур; 4) осознания сходств и различий в социокультурных нормах, стереотипах и культурных кодах Я1 и Я2. 
Таким образом, названные компоненты обеспечивают способность и готовность будущих учителей иностранного языка к переключению культурных кодов в зависимости от глобальной цели коммуникации и ее локальных задач. Умение эффрективно выстроить взаимодействие в ситуации межкультурного контакта свидетельствуют о сформированности процессуального компонента межкультурной коммуникативной компетенции. Его становление осуществляется в процессе поэтапной подготовки обучающихся через овладение целым рядом когнитивных и операциональных умений, определяющих базовое ядро теоретических и практических дисциплин.

Описанное выше содержание знаний и ценностных ориентаций, составляющих основу критической межкультурной осознанности, требует от учителя иностранного языка глубокого понимания сходств и различий в лингвокультурах Я1 и Я2. Усиление сопоставительного аспекта в подготовке будущего педагога-профессионала в области иностранных языков и культур является актуальным требованием современной образовательной практики, ориентированной на критическую осознанность в межкультурной коммуникации. Корректно применяя умения сопоставительного анализа языков и культур, коммуникант определяет факторы, способствующие или препятствующие установлению межкультурных контактов, и объясняет условия, приводящие к благоприятному достижению коммуникативной цели или коммуникативному шоку. По нашему мнению, формирование и дальнейшее развитие умений сопоставительного анализа как важной части межкультурной осознанности учителя иностранного языка должно затрагивать как минимум три сферы.

Во-первых, профессиональная подготовка учителя иностранного языка должна включать работу по формированию у студентов умений сопоставительного лингвистического анализа языковых систем Я1 и Я2, а также речевых произведений на Я1 и Я2. Этот анализ должен затрагивать разные уровни сопоставления, оперировать разными единицами сопоставления и, соответственно, приводить к формированию умений сопоставительного типологического, семантического, синтаксического, функционально-стилистического, переводоведческого анализа и др.

Во-вторых, важнейшей частью профессиональной компетенции учителя иностранного языка должны стать умения сопоставительного лингводидактического анализа, который ориентируется на категориальные явления Я1 и Я2 и имеет принципиальное значение для того, чтобы педагог мог корректно прогнозировать и нивелировать негативную межъязыковую и социокультурную интерферецию, возникающую у обучающихся, либо создавать благоприятные методические условия для положительного межъязыкового и социокультурного переноса в процессе овладения учащимися Я2.

В-третьих, необходимо внедрение элементов сопоставительной культурологии (comparative cultural studies) в программы учебных дисциплин, относящихся к областям теории и практики межкультурной коммуникации, теории и практики перевода, стилистики и интерпретации текста. Применение исследовательского метода кейс-стади позволит будущим учителям иностранного языка сначала изучить сходства и различия признаков культурно-специфических систем Я1 и Я2 в их локальных проявлениях (в отдельных текстах, коммуникативных ситуациях, дискурсивных событиях), а затем экстраполировать эти признаки в целом на культурные стандарты двух лингвокультур. Посредством сопоставительного лингвокультурологического анализа будущие учителя расширяют свои представления о национальных картинах мира, воплощенных в Я1 и Я2, занимают рефлексивную позицию по отношению к паттернам мировоззрения в двух лингвокультурах.

Подчеркнем, что усиление сопоставительного аспекта в анализе языков и культур как важного источника критической межкультурной осознанности невозможно без развития дискурсивной компетенции будущих учителей иностранного языка. Согласно «Общеевропейским критериям языкового образования» («Common European Framework of Reference for Languages») [11], дискурсивная компетенция является частью общей прагматической компетентности коммуниканта. Дискурсивная компетенция представляет собой готовность говорящего организовывать высказывание с учетом требований дискурсивной ситуации: функционально-смысловой и логической организованности, глобальной цельности и локальной связности, тематической и стилевой адекватности, риторической эффективности, кооперативности в коммуникации (постулатов Г. Грайса). В «Общеевропейских критериях языкового образования» подчеркивается, что значимость дискурсивной компетенции возрастает по мере возрастания иноязычной компетентности [11, р. 123]. Цель профессиональной подготовки учителя иностранного языка - формирование интерлингвокультурной языковой личности с высоким уровнем владения Я2, и, очевидно, именно высокое развитие дискурсивных умений становится отличительной чертой такой языковой личности.

Современный подход к анализу дискурса - критический дискурс-анализ - базируется на положении, что именно дискурс «организует» культуру, а бытование языка представляет собой разновидность социокультурной практики [12]. Соответственно, важную часть межкультурной компетентности специалиста составляет знание дискурсивной специфики функционирования Я1 и Я2, осознание того, как именно дискурс одновременно детерминирует социальный контекст и является социально детерминированным. Теоретическая подготовка учителя иностранного языка в области дискурса должна включать, во-первых, знание отношений между единицами Я2 и условий их употребления в определенных коммуникативно-прагматических контекстах и дискурсивных ситуациях и, во-вторых, знание конвенциональных форм коммуникативного поведения и форм организации дискурса, отражающих разделяемые членами инокультурного социума знания, оценки, ценностные ориентации.

Помимо теоретической дискурсивной подготовки будущих учителей иностранного языка, необходим комплекс мер по развитию сложных дискурсивных умений и формированию готовности эффективно участвовать в разнообразных дискурсивных практиках, характерных для лингвокультуры Я2, с учетом их сходств и отличий от дискурсивных практик Я1. Если обобщенно представить дискурсивную компетенцию в области межкультурной коммуникации по основным 
четырем параметрам организации дискурса (гибкость, взаимодействие, развертывание, связность), то данный вид компетенции будет включать:

1) умения определять цели межкультурной коммуникации, оценивать ее условия, соблюдать закономерности порождения/интерпретации дискурса в зависимости от его типа и жанра, учитывать экстралингвистический контекст межкультурной коммуникации;

2) умения применять дискурсивные стратегии и тактики межкультурного взаимодействия, использовать адекватные средства аргументации с учетом действительных или предполагаемых реакций адресата как носителя другой культуры, адекватно применять те средства дискурсивного выдвижения (актуализации) для управления вниманием адресата, которые приняты в лингвокультуре Я2;

3) умения применять и воспринимать социокультурно приемлемые жанровые схемы для развертывания дискурса, адекватно порождать и воспринимать дискурсивные отрезки разных типов, составляющие структуру речевого произведения на Я2, использовать компоненты актуального членения предложения для объективного представления и/или эмфатического выделения новой информации на Я2;

4) умения обеспечить содержательно-смысловую целостность и внутреннюю лексико-грамматическую связность речевого произведения на Я2 с учетом актуальной дискурсивной ситуации, использовать дискурсивные маркеры разных типов, позволяющие установить отношения между отрезками дискурса в ситуациях межкультурного взаимодействия.

В процессе развития перечисленных дискурсивных умений повышается уровень критической межкультурной осознанности, поскольку реализация этих умений требует высокой коммуникативной мотивированности, выраженного намерения достичь коммуникативной цели и осознанного контроля реализации ситуативной программы межкультурной деятельности.

В заключение отметим, что критическая межкультурная осознанность, как и другие виды осознанности, имеет метакогнитивную природу (подробнее о метапознании в межкультурной коммуникации см.: [13]). Метакогнитивная природа осознанности заключается в сложном взаимодействии нескольких видов знания (лингвистического, экстралингвистического, предметного декларативного, предметного процедурного, знания условий деятельности и др.) и механизмов саморегуляции деятельности (осознание стратегий межкультурного взаимодействия, определение условий межкультурной коммуникации, выбор средств, их корректное применение, оценка результата коммуникации). Подготовка учителя иностранного языка требует учета сложной структуры межкультурной коммуникативной компетентности и ведущей роли критической осознанности в этой компетентности. В основу подготовки учителя иностранного языка должно быть положено требование холистического подхода к формированию совокупности знаний Я1 и Я2, ценностно- смысловых ориентаций в области лингвокультур Я1 и Я2, метаязыковой и культурной рефрлексии, умений и навыков межкультурного взаимодействия, готовности к осуществлению речеязыковой деятельности в конкретных актах коммуникации на Я1 и Я2.

1. Byram M. Teaching and Assessing Intercultural Communicative Competence. Clevedon, UK : Multilingual Matters, 1997. $136 \mathrm{p}$.

2. Byram M. Language awareness and (Critical) Cultural Awareness - Relationships, Comparisons and Contrasts // Language Awareness. 2012. Vol. 21. P. 5-13.

3. Leung K., Ang S., Tan M. L. Intercultural Competence // The Annual Review of Organizational Psychology and Organizational Behaviour. 2014. No. 1. P. 489-519.

4. Stone N. Conceptualising Intercultural Effectiveness for University Teaching // Journal of Studies in International Education. 2006. Vol. 10, No. 4. P. 334-356.

5. Siqueira S. English as a Lingua Franca: For a Critical Intercultural Pedagogy // Intercultural Communication. New Perspectives from ESL / Ed. by L. Lopriore and E. Grazzi. Roma : Roma Tree-Press, 2016. P. 189-209.

6. Crozet Ch. The Intercultural Foreign Language Teacher: Challenges and Choices // The Critical Turn in Language and Intercultural Communication Pedagogy: Theory, Research and Practice. Ed. by M. Dasli and A. R. Diaz. New York ; London : Routledge, 2017. P. 143-161.

7. Прохоров Ю. Е. Национальные социокультурные стереотипы речевого общения и их роль в обучении русскому языку иностранцев. М. : УРСС, 1996. 224 с.

8. Гудков Д. Б. Теория и практика межкультурной коммуникации. М. : Гнозис, 2003. 288 с.

9. Liu J., Fang F. Perceptions, Awareness and Perceived Effects of Home Culture on Intercultural Communication: Perspectives of University Students in China // System. 2017. No. 67. P. 25-37.

10. Zhu H. From Intercultural Awareness to Intercultural Empathy // English Language Teaching. 2011. Vol. 4, No. 1. P. 116-119.

11. Common European Framework of Reference for Languages. Cambridge : Cambridge University Press, 2001. $260 \mathrm{p}$.

12. Fairclough N. Critical Discourse Analysis: The Critical Study of the Language. Second Edition. London ; New York : Routledge, 2010.591 p.

13. Sieck W. R. Metacognition in Intercultural Communication // The International Encyclopedia of Intercultural Communication / Ed. by Y. Y. Kim and K. L. McKay-Semmler. Wiley-Blackwell, 2017. URL: https://www.globalcognition.org/ wp-content/uploads/articles/sieck-IEICC-17-metacognitionintercultural-communication.pdf (дата обращения: 20.01.2020).

(C) Деревянченко Е. А., Устинова Т. В., 2020 